\title{
Evaluación del efecto biocontrolador de Bacillus spp., frente a Fusarium spp., bajo condiciones de invernadero en Rosmarinus officinalis $L$.
}

\author{
Lucia Constanza Corrales, $M S^{1}$, Ligia Consuelo Sánchez $\mathrm{MSc}^{1}$, \\ Jairo Cuervo PhD², Diana Bautista³, Lady González³ , Marcela Guevara³ \\ 1. Docentes investigadoras. Universidad Colegio Mayor de Cundinamarca. Bogotá, Colombia. \\ 2. Docente investigador. Universidad Nacional de Colombia. \\ 3. Estudiantes. Programa de Bacteriología y Laboratorio Clínico, Facultad de Ciencias de la Salud. Universidad \\ Colegio Mayor de Cundinamarca. Bogotá, Colombia. \\ Correspondencia: Icorralesr07@gmail.com
}

Recibido: 03-18-2011 / Aceptado: 05-04-2011

\section{Resumen}

El romero es una de las plantas aromáticas más importantes dentro del mercado de exportación colombiano. El cultivo de esta planta se ve afectado por marchitez vascular producida por Fusarium spp. El objetivo principal de este trabajo fue establecer en el romero el efecto biocontrolador de Bacillus spp., frente a Fusarium spp., bajo condiciones de invernadero. Para ello se seleccionaron Bacillus liqueniformis (BI), Bacillus subtilis (B2), Bacillus megaterium (B I4), Bacillus brevis (E2), aislados de rizósfera de plantas aromáticas, a los cuales se les realizaron pruebas de viabilidad, identificación enzimática manual y automatizada, y pruebas de antagonismo in vitro en medio PDA frente a Fusarium acuminatum aislado de las plantas de romero, comprobando la patogenicidad del hongo por postulados de Koch.

El ensayo se realizó con 30 plántulas de romero, un control negativo y uno positivo, bioensayos con sólo Bacillus spp., y tratamientos con Bacillus spp., más el patógeno. Para evaluar la severidad del patógeno y el comportamiento de las bacterias cada ensayo se realizó por triplicado y bajo condiciones de invernadero. En las pruebas de antagonismo in vitro BI y B2 presentaron entre el 70-100\% de inhibición del micelio y BI 4 y E2 entre el 40-69\%. Los Bacillus spp., disminuyeron la severidad de la marchitez vascular en todos los ensayos; por la producción de sustancias antifúngicas facilitaron el aumento del peso seco de las hojas de las plantas al permitir la obtención de nutrientes y B I 4 aumentó la longitud de la raíz y el tallo. Se precisa secuenciar el aislamiento de Fusarium, para confirmar la especie. Palabras clave: fitopatógeno, marchitez vascular, Rosmarinus officinalis $L$.

\section{Abstract \\ Evaluation of biocontrol effect of Bacillus spp. vs. Fusarium spp. under greenhouse conditions in Rosmarinus officinalis $L$. \\ This study evaluates the effect of the genus Bacillus sp as biological control of fungal phytopathogens in plants, mostly through antagonistic relations that induce cell death in natural way. Fusarium oxysporum is}


well-known pathogen related with vascular wilt and root rot in a variety of plants; colonizing the vessels and blocking them to cause yellowing of leaves due to the impossibility in the transport of nutrients, causal of serius economic loss in national agriculture. Several mechanisms have been established to control this filamentous fungi within which are the extensive and variable use of agrochemicals and pesticides, but due its harmful effects to the environment, has begun to replace by the use of the genus Bacillus. Its biocontrol effect is mediated by the biochemical profile, as they produce multiple biologically active metabolites; Bacillus subtilis produces fengycin and iturin A, and Bacillus brevis and gramicidin S ( I-5), able of inhibit the normal growth and development of other organisms, this suggest its use as a biocontrol of pests to strengthen the current environmental quality standards.

Keywords: Bacillus sp, Fusarium oxysporum, biocontrol, genes, metabolites.

\section{Introducción}

El cultivo de romero (Rosmarinus officinalis L.), es uno de los más importantes dentro del mercado de plantas aromáticas y medicinales en el mundo; debido a que de éste se obtienen aceites esenciales estimulantes y tónicos medicinales para perfumería, además de que es utilizado como condimento (1). Colombia presenta una condición de alta heterogeneidad en la siembra de especies de plantas aromáticas, siendo el departamento de Cundinamarca el de mayor área de cultivo, principalmente de romero (2). Las plantas de romero pueden ser afectadas por varios fitopatógenos, entre los que se destaca el Fusarium spp., ocasionando marchitez vascular, lo cual provoca pérdidas económicas y de confiabilidad en el producto, dispersión del patógeno en los cultivos aledaños y contaminación de suelo y agua por la utilización de agroquímicos para combatirlo.

Es importante resaltar que Colombia exporta hierbas aromáticas principalmente a Norteamérica y Europa (2). La producción del romero como hierba aromática condimentaria y especialmente como esencia, se perfila como una actividad promisoria (3). Las exportaciones de éstas especias se perjudican, cuando las aromáticas no se encuentran en un estado fitosanitario óptimo y por ende las ganancias de los cultivadores y empresarios disminuye.

El manejo convencional de los problemas fitosanitarios por parte de los agricultores se basa en la aplicación de químicos, generando deterioro en los suelos y disminución en la calidad del producto agrícola. Razón por la cual en los últimos años las investigaciones están encaminadas a plantear sistemas de control de fitopatógenos, usando biocontroladores como alternativa para mantener el equilibrio en los ecosistemas agrícolas. La utilización de microorganismos saprófitos, especialmente seleccionados, pertenecientes a la flora de los suelos agrícolas para controlar fitopatógenos, representa una importante herramienta y una alternativa de control biológico (4). Entre los microorganismos más utilizados para el control de fitopatógenos fúngicos se encuentra el género Bacillus spp. $(5,6)$, debido a que tienen la facilidad de digerir la quitina, además de la producción de antibióticos como: bacitracina, polimixina, tirocidina, gramicidina y circulina, entre otros (7). Este estudio plantea una posible alternativa para el control de la enfermedad, al establecer el efecto biocontrolador de Bacillus spp., frente a Fusarium spp., bajo condiciones de invernadero en plantas de romero durante su etapa vegetativa, experimento que se realizó en los invernaderos de la Universidad Nacional de Colombia, Sede Bogotá.

\section{Materiales y métodos}

Las bacterias utilizadas en este estudio fueron aisladas de rizósfera de mejorana, tomillo, estragón, estrellita de Belén y albahaca, en proyectos anteriores realizados con el grupo de investigación CEPARIUM 
de la Universidad Colegio Mayor de Cundinamarca.

Recuperación de microorganismos aislados de rizósfera de plantas aromáticas. El procedimiento para la descongelación de los microorganismos en éste estudio fue realizado de acuerdo al protocolo descrito por Corrales y Sánchez en el 2005, con modificaciones (8). Los viales de las cepas utilizadas correspondían a L2, L3, L4, L7, L10 aisladas con anterioridad de la planta estrellita de Belén (9); H4, AHE, A. iwoffi, MISC, 9.5.1, 7.4.1, 7.4, 4.5, 3.5, 2.5, 2.4, 4.4, 1.5 aisladas de mejorana (10); E4, E2, E1 aisladas de estragón(11); B1, B2, B3, B4 aisladas de tomillo (12); y B14 aislada de albahaca (13), para un total de 26 microorganismos.

Identificación de los microorganismos seleccionados. Se seleccionaron siete cepas de acuerdo a las características de viabilidad y de crecimiento que presentaron. Se realizó la identificación a las cepas seleccionadas (9.5.1, B1, B2, B3, B4, E2, B14), a través de pruebas bioquímicas manuales (TSI, citrato de Simmons, urea, motilidad, nitritos, $\mathrm{NaCl} 4.5 \%$, glucosa, xilosa, arabinosa, almidón) y automatizadas por el sistema BBL CRYSTAL.

Aislamiento e identificación del patógeno. Se utilizó un aislamiento de Fusarium spp., obtenido anteriormente de plantas de romero (Rosmarinus officinalis) que presentaban signos y síntomas de marchitez vascular de cultivos de la Universidad Nacional, sede Bogotá. A éste se le realizó coloración con azul de lactofenol, para la identificación microscópica por claves taxonómicas específicas del género Fusarium (Fuskey).

Pruebas de patogenicidad. Con el fin de determinar sí el aislamiento proporcionado por la Universidad Nacional de Colombia era el causante de marchitez vascular en romero (Rosmarinus officinalis); se realizaron pruebas de patogenicidad en las plántulas de un mes, con cuatro repeticiones; la evaluación se efectuó a los ocho días con la medición de severidad.

Las plántulas fueron lavadas con agua de chorro y sometidas a desinfección con hipoclorito de sodio al $10 \%$ por 5 minutos, posteriormente fueron lavadas con abundante agua destilada estéril y sumergidas en alcohol al $70 \%$, luego se dejaron secar en toallas absorbentes (14). En un ambiente antiséptico se hizo una herida en la base del tallo, sobre la misma se colocó el inóculo (el hongo con 15 días de desarrollo en medio PDA), cubriendo la zona tratada con gasa humedecida en agua destilada estéril. Las plantas control fueron sometidas al mismo tratamiento colocándoles solamente gasa humedecida (15).

Cada uno de los tratamientos fue sembrado en turba estéril a capacidad de campo. Las plantas se mantuvieron en cámara húmeda constituida por bolsas de plástico transparentes. Tanto las plantas inoculadas como los controles fueron mantenidos a $23^{\circ} \mathrm{C} \pm 3^{\circ} \mathrm{C}$ bajo condiciones de invernadero (15). Estas fueron evaluadas macroscópicamente y al estereoscopio a los ocho días para observación de los haces vasculares a través de un corte longitudinal en el tallo. Para la determinación de los postulados de Koch los tallos se sembraron en agar Rosa de Bengala y PDA con el fin de obtener el patógeno; la confirmación de las estructuras microscópicas se realizó con coloración de azul de lactofenol.

Prueba de enfrentamiento directo. Para observar el potencial antagónico in vitro de las bacterias B1, B2, B3, B4, E2, 9.5.1 y B14 contra Fusarium spp., se utilizó la metodología empleada por Acosta y Avellaneda (12), con algunas modificaciones. Se sembró el fitopatógeno en el centro de una caja de Petri y cuatro biocontroladores por estría a una distancia de $3 \mathrm{~cm}$ respecto al patógeno. Los ensayos se sembraron por triplicado en agar PDA por 7 días a $28^{\circ} \mathrm{C}$, y al mismo tiempo se hizo un control del crecimiento del aislamiento del Fusarium spp., utilizado (12).

La tasa de crecimiento micelial se dio en centímetros por día, se determinó teniendo en cuenta el radio de crecimiento de la colonia fúngica calculando su magnitud mediante la expresión sugerida por Mead (9):

$$
\text { T.C }=(\mathrm{Cf}-\mathrm{Ci}) /(\mathrm{Tf}-\mathrm{Ti})
$$

El porcentaje de inhibición del crecimiento micelial se calculó empleando la fórmula de Samaniego y colaboradores, citado por Acosta y Avellaneda (12).

$$
\% \text { inhibición }=((\mathrm{R} 1-\mathrm{R} 2) / \mathrm{R} 1)^{*} 100
$$

El comportamiento de inhibición mostrado por los diferentes aislamientos se agrupó de la siguiente manera (9): 
- Negativo: ausencia de zona de inhibición o un porcentaje menor de $10 \%$ y crecimiento normal de la colonia fúngica, de forma similar al control.

- Baja: ausencia de zona de inhibición o con un porcentaje entre 10-39\% y con disminución en el crecimiento de la colonia fúngica.

- Media: ausencia de zona de inhibición o un porcentaje entre 40-69\% y con disminución en el crecimiento de la colonia fúngica.

- Positivo: presencia de zona de inhibición definida o en un porcentaje entre $70-100 \%$.

Material vegetal. Se sembraron 200 plántulas de romero (Rosmarinus officinalis) por esqueje en una bandeja en el invernadero de propagación de la Universidad Nacional de Colombia. Después de un mes, se seleccionaron 30 plántulas homogéneas en tamańo, sin signos y síntomas de enfermedad.

Preparación del inóculo del patógeno. Para la preparación del inóculo de Fusarium spp., se utilizó un hongo de 15 días de crecimiento en medio PDA. A éste se le agregó $20 \mathrm{~mL}$ de agua destilada estéril y se raspó con un asa para despegar los conidios. Posteriormente, se filtró la suspensión con dos gasas estériles (16) y se agitó en vortex durante un minuto. Luego se agregó esta suspensión a frascos estériles de $75 \mathrm{~mL}$ con agua destilada estéril. Después se realizó un recuento de conidios en cámara de Neubauer, para obtener una concentración de $1 \times 10^{6}$ conidios $/ \mathrm{mL}$ y con ayuda de un bisturí a las plantas se les cortó $10 \mathrm{~mm}$ de la base del tallo, inoculando en esta $1 \mathrm{~mL}$ de la suspensión de Fusarium spp., con jeringa. En los controles negativos se reemplazó el inóculo de Fusarium spp., por agua destilada estéril (12).

Preparación del inóculo de los biocontroladores. Para la preparación del inóculo de los biocontroladores se realizó siembra de las bacterias en agar MuellerHinton, a las 24 horas de crecimiento de estas se preparó en caldo $\mathrm{BHI}$ la concentración estandarizada a $10^{8} \mathrm{UFC} / \mathrm{mL}$, usando la escala de Mac Farland (17).

Montaje del bioensayo. Cuando las plántulas alcanzaron una altura promedio de $10 \mathrm{~cm}$ se procedió a medir la longitud del tallo, raíz y longitud total por planta. Se lavaron con agua destilada estéril para eliminar el exceso de suelo y se hizo un corte en la base del tallo bajo condiciones asépticas (14). Luego se sumergieron en frascos que contenían las suspensiones bacterianas B14, E2, B1, B2 durante $15 \mathrm{~min}$ (18). A las 24 horas fue inoculado por inyección $1 \mathrm{~mL}$ de la suspensión del patógeno en la herida realizada en la base del tallo. Las plántulas fueron colocadas bajo condiciones de invernadero durante 35 días bajo una polisombra. En el ensayo se montó un testigo positivo y uno negativo, cuatro bioensayos que contenían sólo los Bacillus spp., biocontroladores y cuatro tratamientos que contenían cada uno los Bacillus spp., con el patógeno, todos estos por triplicado.

Evaluación de la severidad. Las plantas fueron evaluadas cinco veces durante 35 días. La evaluación de la severidad se llevó a cabo mediante la elaboración de una escala establecida por primera vez para esta especie vegetal, Figura 1, y se utilizó la fórmula de Castaño $(19,20)$ :

$$
\text { severidad }(\%)=\frac{\sum(\mathrm{n} * 1)}{N}
$$

Severidad \%: severidad de la enfermedad expresada en porcentaje del tejido afectado.

$\mathrm{n}$ : número de unidades de muestreo clasificadas en cada clase.

I: $\quad$ índice de severidad por cada clase.

$\mathrm{N}$ : $\quad$ número total de unidades de muestreo observadas.

\section{Confirmación del patógeno en haces vasculares.} Se realizaron cortes longitudinales a los tallos, con el fin de observar a través del estereoscopio los haces vasculares de todas las plantas del ensayo, identificando síntomas internos de marchitez vascular; posteriormente se sembró en agar PDA dos segmentos de estos tallos, previa limpieza y desinfección, con el fin de confirmar la presencia o ausencia del hongo fitopatógeno.

Evaluación del crecimiento y peso seco. Al finalizar el ensayo se procedió a medir la longitud del tallo y raíz para determinar diferencias entre estas. Las plantas fueron llevadas a un horno a $70^{\circ} \mathrm{C}$ por tres días para determinar su peso seco.

\section{Resultados}

Recuperación de microorganismos aislados de rizósfera de plantas aromáticas. Los 26 microorganismos descongelados presentaron 


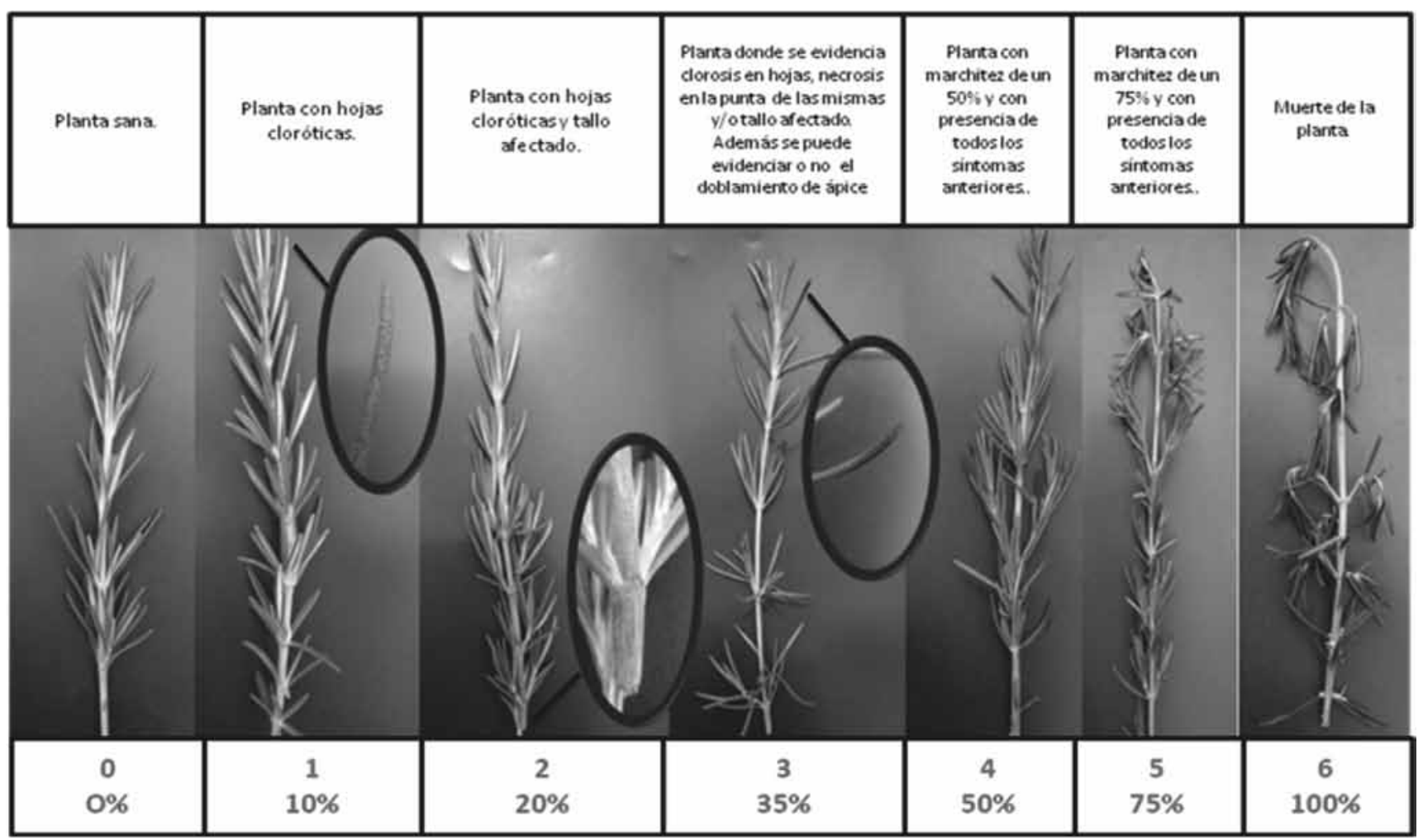

Figura 1. Escala de severidad en romero establecida por Bautista, González y Guevara.

crecimiento en caldo BHI después de 24 horas, esta lectura se evidenció a través de la turbidez del caldo. De éstos, se seleccionaron siete de acuerdo a los siguientes criterios: morfología, tamaño, abundancia y presencia de esporasen la coloración de Gram, mejor crecimiento en agar sangre y ausencia de contaminación.

\section{Identificación de microorganismos seleccionados} Los resultados de las pruebas bioquímicas manuales se ven en la Tabla 1 y los de las pruebas automatizadas (BBL CRYSTAL) en la Tabla 2.

Identificación del patógeno. Las características microscópicas y macroscópicas del fitopatógeno concuerdan con Fusarium acuminatum, Tabla 3.
A) Colonia de Fusarium aislado de romero.

B) Esporodoquios de color amarillo, Figura 2.

A) macroconidias de $25 \mu \mathrm{m}$ con 4-6 septos, sin coloración, observación microscópica 40x.

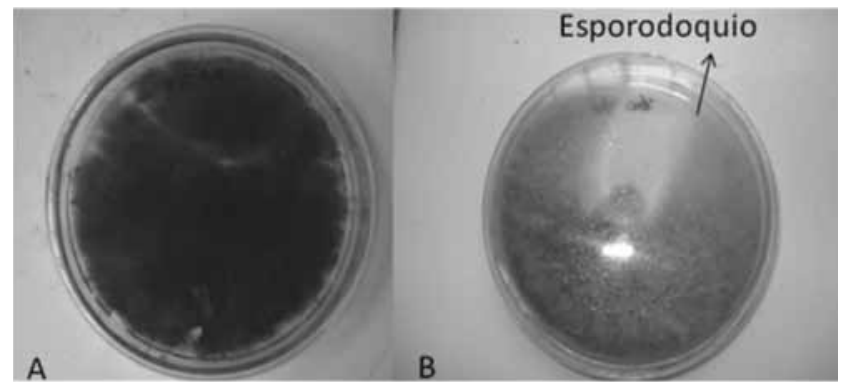

Figura 2. Características macroscópicas de Fusarium sp., en agar PDA

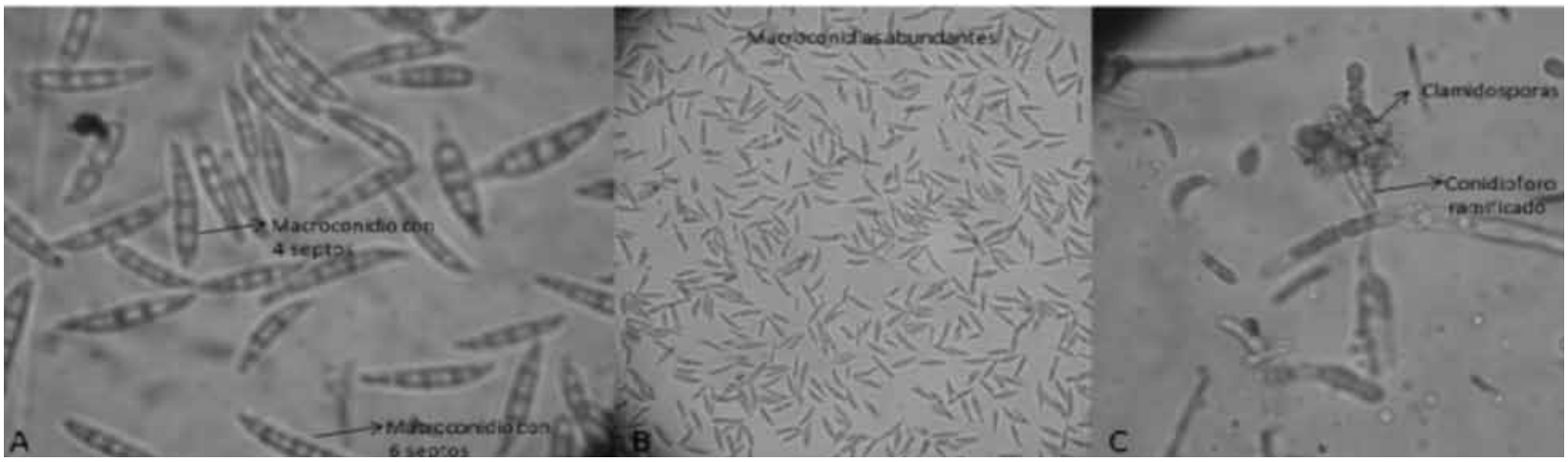

Figura 3. Observación microscópica de las estructuras del aislamiento del Fusarium spp. 
Tabla 1. Actividad enzimática por pruebas bioquímicas manuales.

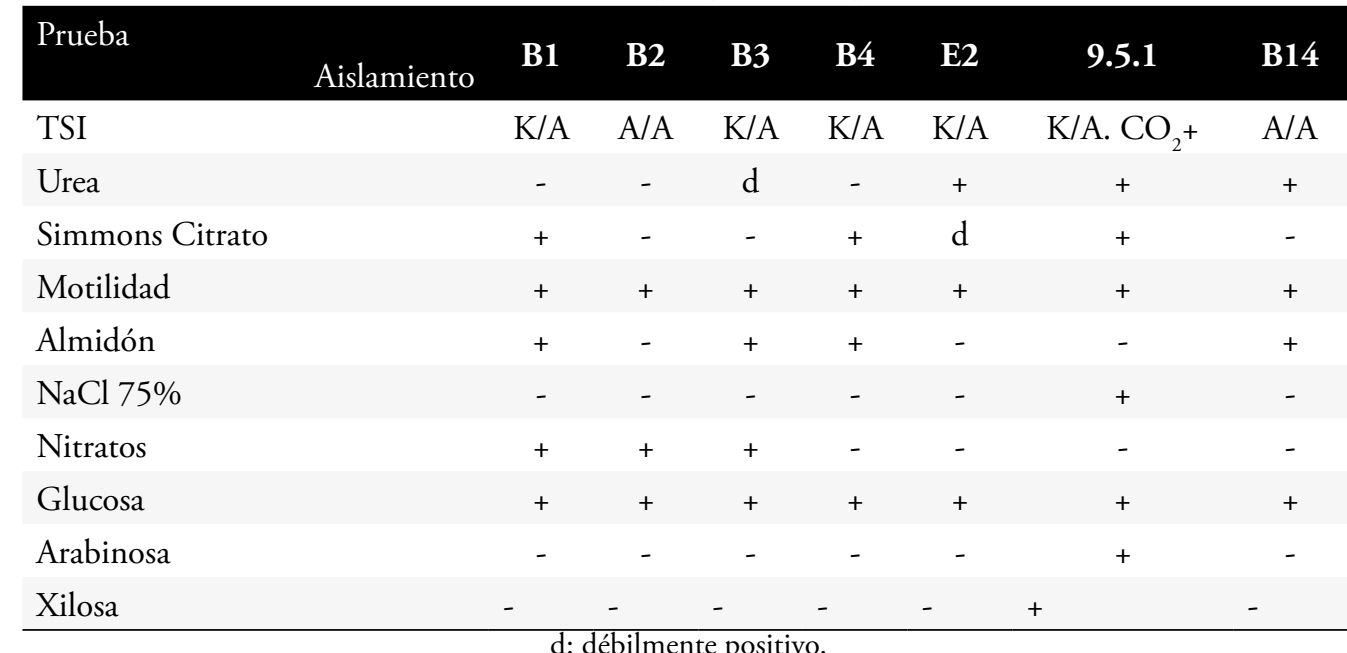

Tabla 2. Identificación de microorganismos por actividad enzimática en método automatizado.

\begin{tabular}{|c|c|c|}
\hline Aislamiento & $\begin{array}{l}\text { \% de confiabilidad } \\
\text { (BBL CRYSTAL) }\end{array}$ & $\begin{array}{c}\text { Microorganismo } \\
\text { identificado }\end{array}$ \\
\hline B1 & $\begin{array}{l}\text { Código: } 2334571752 \\
96 \%\end{array}$ & Bacillus liqueniformis \\
\hline B2 & $\begin{array}{l}\text { Código: } 2014463753 \\
99.5 \%\end{array}$ & Bacillus subtilis \\
\hline B3 & $\begin{array}{l}\text { Código: } 2334463773 \\
94 \%\end{array}$ & Bacillus subtilis \\
\hline B4 & $\begin{array}{l}\text { Código: } 3571411765 \\
99 \%\end{array}$ & Bacillus cereus \\
\hline 9.5 .1 & $\begin{array}{l}\text { Código: } 3575535771 \\
80 \% \\
12 \%\end{array}$ & $\begin{array}{l}\text { Oerskovia spp. } \\
\text { Bacillus liqueniformis }\end{array}$ \\
\hline B14 & $\begin{array}{l}\text { Código: } 2664471473 \\
99 \%\end{array}$ & Bacillus megaterium \\
\hline E2 & $\begin{array}{l}\text { Código: } 2574000643 \\
99 \%\end{array}$ & Bacillus brevis \\
\hline
\end{tabular}

Tabla 3. Características macroscópicas y microscópicas de un aislamiento de Fusarium spp., en romero.

\section{CARACTERÍSTICAS MACROSCÓPICAS \\ CARACTERÍSTICAS MICROSCÓPICAS}

Colonia inicialmente blanca, algodonosa, densa; con la edad se Microscópicamente el aislamiento presentaba microconidias torna de color vino intenso, Figura 2A. ausentes.

En agar PDA presentó esporodoquios con una pigmentación que Macroconidias de curvatura moderada, presentan de 4-6 va de amarillo a naranja melón en el micelio, Figura 2B. septos, anchas en el centro, muy abundantes, Figura 3A y $3 \mathrm{~B}$. Se observaron conidióforos ramificados, Figura 3C. Clamidosporas ovales, globosas e indistintamente ubicadas, Figura 3C.

B) macroconidias abundantes en cámara de Neubauer, observación microscópica 10x. C) clamidosporas globosas y conidioforo ramificado con azul de lactofenol, observación microscópica 40x. Bautista, González y Guevara (2009).
Pruebas de patogenicidad. Los cuatro tratamientos presentaron signos y síntomas de marchitez vascular macroscópica y al estereoscopio. El control negativo no presentó signos ni síntomas. En agar rosa de Bengala y PDA, se evidenció el crecimiento de un 

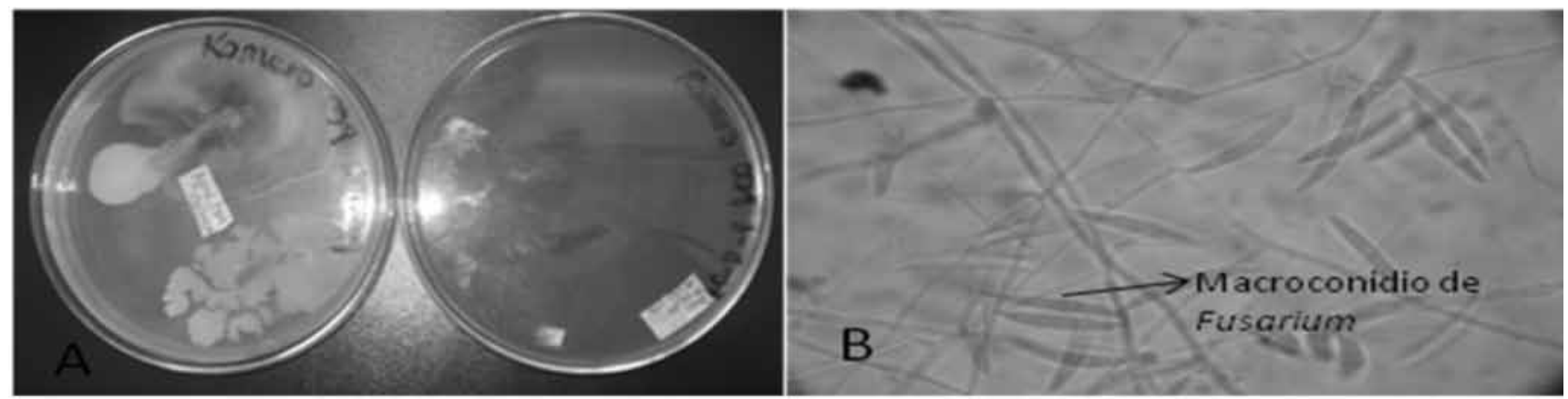

Figura 4. Crecimiento del hongo en agar PDA y Rosa de Bengala y observación microscópica.

A) Aislamiento del fitopatógeno en agar PDA, y rosa de bengala. B) Observación microscópica en 40x con coloración de azul de lactofenol del hongo crecido en agar PDA. Bautista, González y Guevara (2009).

hongo con micelio rojo claro el cual concuerda con el Fusarium inoculado como se observa en la Figura $4 \mathrm{~A}$, en la coloración de azul de lactofenol muestra características compatibles con el fitopatógeno estudiado como se observa en la Figura 4B.

Prueba de enfrentamiento directo. Los Bacillus analizados resultaron ser eficientes contra el ataque del Fusarium spp., aislado en las pruebas in vitro. Los resultados del porcentaje de inhibición y la tasa de crecimiento micelial frente al patógeno se hicieron en base al promedio de las tres repeticiones por bacteria, estos datos se referencian en la Tabla 4 y Figuras 5 y 6 . B1 y B2 fueron positivas presentando un porcentaje entre el 70-100\% de inhibición del micelio. B3, B4, B14, E2 y 9.5.1 mostraron una inhibición media con un porcentaje entre 40-69\%. Ninguno de los Bacillus obtenidos tuvo un porcentaje bajo de inhibición ni negativo.

Montaje del bioensayo. Con base en los resultados obtenidos en las pruebas bioquímicas, las pruebas de antagonismo y la pureza de la cepa no se pudo trabajar con las siguientes bacterias: B3 pues correspondía a Bacillus subtilis al igual que B2, pero con menor porcentaje de inhibición; B4

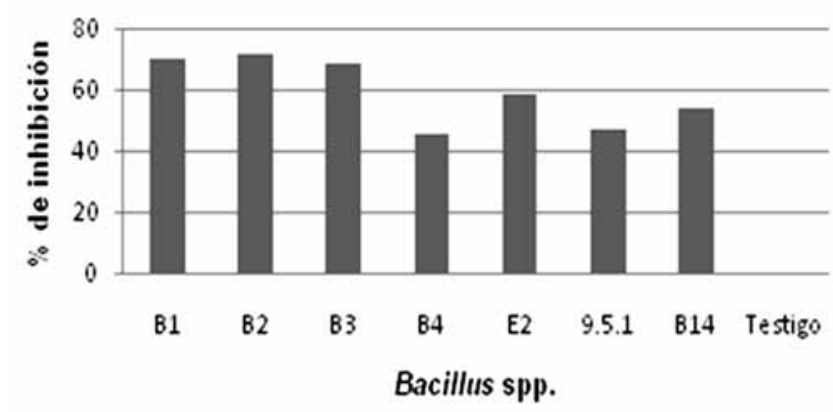

Figura 5. Porcentaje de inhibición de Bacillus spp., frente al aislamiento de Fusarium spp.
Tabla 4. Resultados del porcentaje de inhibición y tasa de crecimiento micelial del aislamiento de Fusarium spp., frente a los

\begin{tabular}{lll}
\multicolumn{3}{c}{ Bacillus spp. } \\
Aislamiento & $\begin{array}{c}\text { \% } \\
\text { Inhibición }\end{array}$ & T.C (cm/día) \\
\hline B1 & 70.21 & 0.18 \\
B2 & 71.91 & 0.17 \\
B3 & 68.52 & 0.2 \\
B4 & 45.27 & 0.36 \\
E2 & 58.11 & 0.27 \\
$\mathbf{9 . 5 . 1}$ & 46.73 & 0.35 \\
B14 & 53.99 & 0.3 \\
Testigo & 0 & 0.67 \\
\hline
\end{tabular}

presentó contaminación al momento de montar el bioensayo y 9.5.1 en la identificación bioquímica arrojó valores de confiabilidad menores a un $90 \%$ : compatibilidad con Oerskovia spp., en un $80 \%$ y con Bacillus liqueniformis en un $12 \%$, por lo tanto no se utilizó. Las bacterias utilizadas para el montaje de la prueba de campo fueron: B1 (Bacillus liqueniformis), B2 (Bacillus subtilis), B14 (Bacillus megaterium) y E2 (Bacillus brevis).

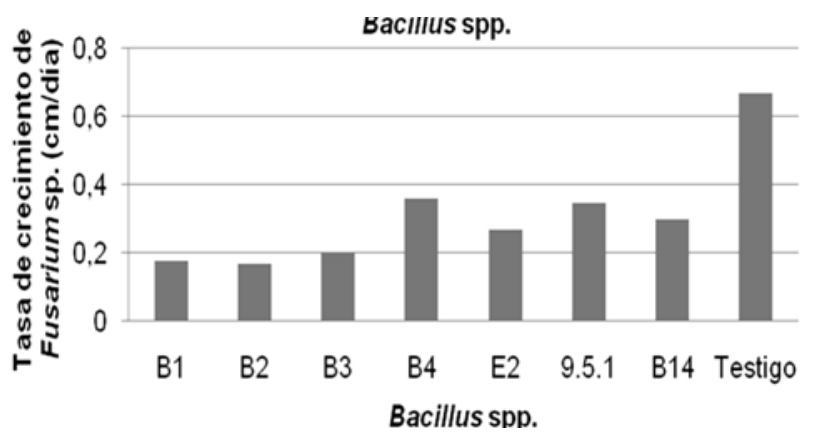

Figura 6. Tasa de crecimiento micelial del aislamiento de Fusarium spp., frente a Bacillus spp. 
Evaluación de la severidad. Los resultados de la severidad se muestran en la Figura 7. Todas las bacterias fueron eficientes frente a Fusarium spp bajo condiciones de invernadero comparado con el control positivo. La menos eficiente fue B14 con un porcentaje de severidad de 31,6\%. E2 y B2 mostraron resultados iguales con $13,3 \%$ y B1 se acerca a estos resultados con $15 \%$.

Confirmación del patógeno en haces vasculares. A través del estereoscopio se pudo observar un color gris claro en los haces vasculares a excepción del testigo positivo donde dos de las tres plantas (A, B y C) mostraron un color marrón. En el momento del corte varias plantas mostraron un endurecimiento en el sitio de inoculación. Los datos del crecimiento del patógeno en medio PDA se observa en la Tabla 5.

Tabla 5. Crecimiento del patógeno en medio PDA.

\section{Ensayos en los que se aisló el Fusarium.}

Testigo positivo $\mathrm{B}$ y $\mathrm{C}$

Tratamiento E2 A y B

Tratamiento B14 B y C

Evaluación del crecimiento y peso seco. En la Figura 8 se observa el porcentaje de crecimiento de la raíz de los bioensayos y testigos. En ésta se evidencia mayor crecimiento en todos los bioensayos respecto a los testigos, sin embargo B14 (Bacillus megaterium) favoreció el mayor crecimiento radicular con un $28.1 \%$ y con una diferencia de $23.6 \%$ respecto al control negativo. El control positivo presentó un crecimiento demasiado bajo con una diferencia de $3.7 \%$ respecto al negativo.

La Figura 9 muestra los resultados obtenidos en el porcentaje de crecimiento del tallo en bioensayos y testigos. El bioensayo con B14 (Bacillus megaterium)

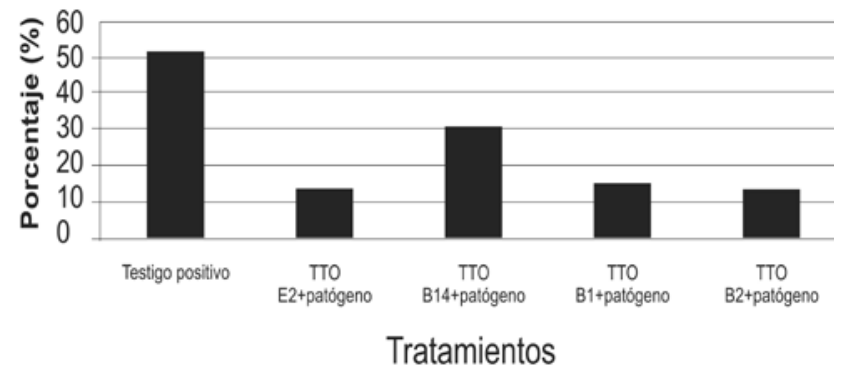

Figura 7. Porcentaje de severidad de marchitez vascular en plantas de romero. presentó el mejor crecimiento con un $18.1 \%$ en comparación con los demás. Si se compara con el control negativo se observa que el crecimiento fue mayor en $1.4 \%$, mostrando una diferencia significativa; los demás bioensayos no mostraron incremento en la longitud del tallo con respecto al control negativo, pero si con respecto al positivo. La Figura 9 también muestra que la presencia del patógeno en el testigo positivo produjo disminución del crecimiento del tallo en un $8 \%$ con respecto al control negativo.

La Figura 10 muestra que se obtuvo mayor peso seco en hojas en todos los tratamientos, en comparación con los bioensayos y los testigos. Sin embargo, fue con B2 el que mostró el mayor porcentaje frente a los testigos. En el montaje de los tratamientos, B14 reveló el valor más alto seguido de B2 con diferencias significativas con respecto a los testigos. Al comparar los resultados obtenidos entre tratamientos, bioensayos y testigos, B2 mostró los resultados más altos. En cuanto al peso seco en raíz, se evidencia que entre bioensayos y tratamientos no hay una diferencia significativa. Sin embargo, E2 obtuvo los mayores resultados con respecto al testigo negativo. En lo relacionado con el peso seco en tallo tampoco se encontraron diferencias significativas entre los resultados de los bioensayos y los tratamientos.

\section{Discusión}

El Fusarium aislado de plantas de romero en la Universidad Nacional de Colombia tiene las características morfológicas de Fusarium acuminatum, las cuales están reportadas por John F. Leslie, Brett A. Summerell, en el libro The Fusarium Laboratory

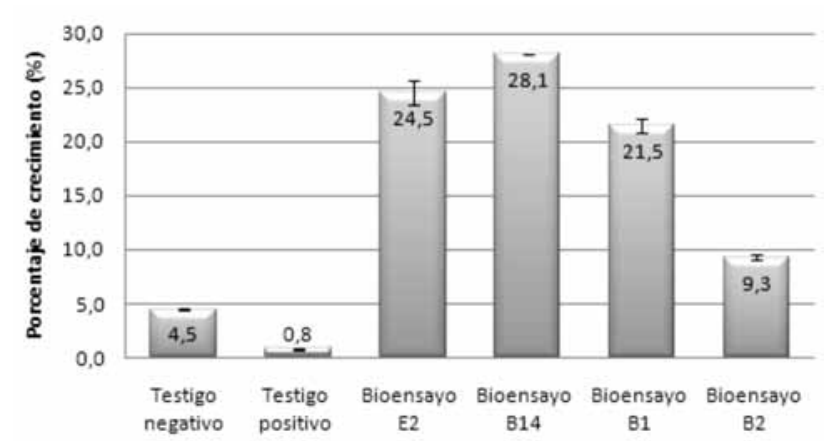

Figura 8. Crecimiento inicial y final de raíz en plantas de romero. 


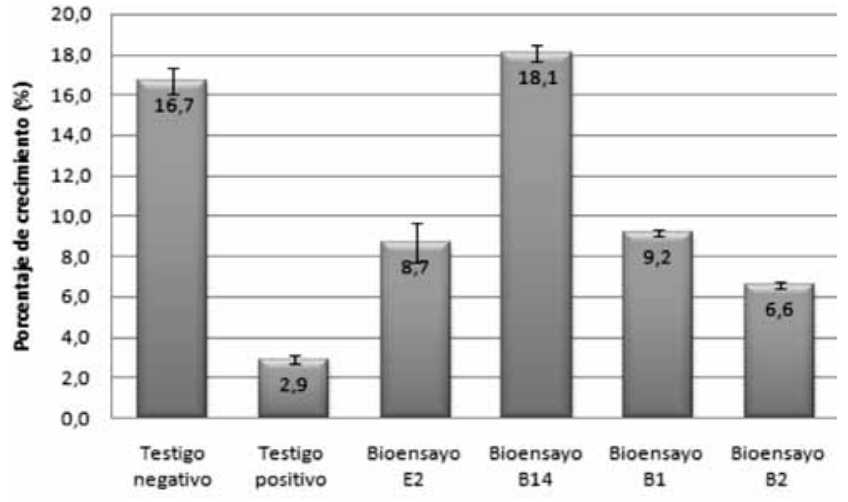

Figura 9. Crecimiento inicial y final de tallo en plantas de romero.

Manual; allí se menciona que el crecimiento de esta especie en agar PDA es lento, el micelio en los primeros días es de color blanco pero posteriormente pasa por colores rosa hasta el vino, en la etapa de formación de esporodoquios se torna de color amarillo, lo cual ocurre después de dos a tres semanas de crecimiento (21). Descripción macroscópica que coincide con las características del aislamiento reportado en el estudio.

En cuanto a la descripción microscópica, se reportan para la especie aspectos como la ausencia o escasez de microconidias, lo cual no representa un indicador taxonómico fiable; sin embargo, aspectos como la curvatura moderada de las macroconidias y el número de septos que va desde cuatro a seis por estructura para Fusarium acuminatum, concuerda con lo encontrado en el aislamiento como lo muestra la Figura 3., así como la formación de clamidosporas lenta en grupos o cadenas (21).

F. acuminatum fue descrito por primera vez por Ellis y Everhart a partir de tallos de papa en Ginebra, Nueva York (22). Este hongo se encuentra en las regiones templadas por lo general como un saprofito del suelo o asociado a las raíces y las coronas de las plantas. En ocasiones puede estar asociado con enfermedades de raíz y corona de una variedad de plantas, sobre todo en legumbres y granos de cereales cultivados en Canadá, Europa y la antigua Unión Soviética (21).

En Colombia no se ha reportado esta especie de Fusarium, como saprófito o patógeno. El Ministerio de Comercio, Industria y Turismo reporta en las estadísticas de importaciones a Colombia, que productos como trigo, cebada, maíz, soya, arroz y legumbres provienen de Canadá, Rusia y algunos

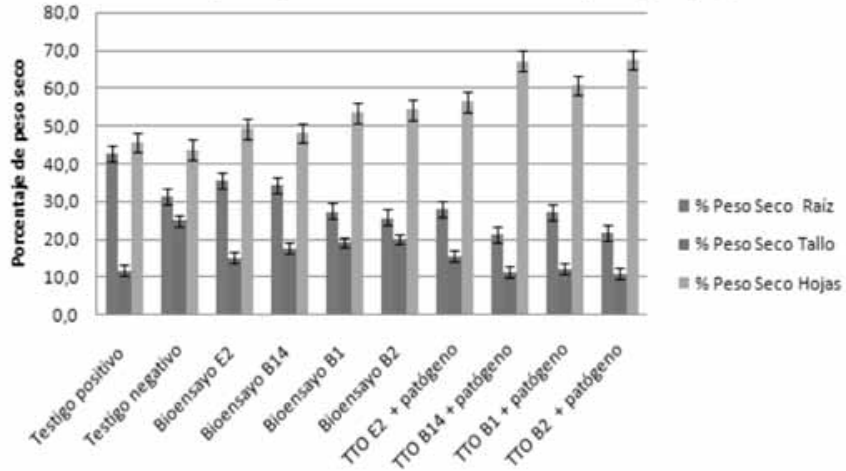

Figura 10. Evaluación de peso seco en raiz, tallo y hojas de plantas de romero.

países de la Unión Europea $(23,24)$, donde se ha identificado esta especie de Fusarium. Lo anterior plantea la posibilidad de que el patógeno haya ingresado al país en estos productos de importación. Por ende se hace esencial realizar la secuenciación de éste aislamiento, con el fin de confirmar la especie y en tal caso hacer el reporte en Colombia.

Se confirmó el Fusarium aislado como agente patógeno a través de los postulados de Koch al demostrarse lo siguiente: el patógeno siempre estuvo asociado con la enfermedad; se aisló en agar PDA, a partir de este se estudiaron sus características específicas; luego se inoculó en plantas sanas las cuales presentaron síntomas característicos de la enfermedad y por último fue reaislado de las plantas inoculadas nuevamente en agar PDA, presentando las mismas características macroscópicas y microscópicas (25).

Todas las bacterias presentaron un buen desempeño en las pruebas antagónicas in vitro, resultado esperado ya que las especies del género Bacillus han sido reportadas como efectivos biocontroladores de múltiples fitopatógenos por su capacidad de producir varios antibióticos de amplio espectro, característica que ha permitido utilizarlos como fungicidas comerciales (26-29).

B1 (Bacillus liqueniformis) y B2 (Bacillus subtilis), presentaron un desempeño positivo en las pruebas in vitro contra Fusarium probablemente por la capacidad de secretar lipopéptidos antibióticos del grupo Iturin cuyo mecanismo de acción va dirigida sobre la permeabilidad de la membrana y la composición lipídica de la célula fúngica, de tal forma que inhibe el crecimiento micelial y la esporulación del hongo (3032). B3, B4, B14, 9.5.1 y E2 presentaron un nivel de 
inhibición medio. B3 (Bacillus subtilis) corresponde a la misma especie que B2 presentando porcentajes de inhibición similares y las mismas características antagónicas; B4 (Bacillus cereus) produce zwittermicin A, con características estructurales similares al quitosano, el cual actúa como antibiótico frente a fitopatógenos (33-35). B14 (Bacillus megaterium) produce amilasas, proteasas, y antibióticos como el megacin, además de otras sustancias antagónicas (36,37). E2 (Bacillus brevis) produce péptidos extracelulares antagónicos que inducen a la hinchazón del citoplasma de las células que conforman las hifas, también inhibe la germinación de conidios, así como la formación del micelio vegetativo del hongo (38); por último 9.5.1 (Oerskovia sp.) no ha sido reportado como biocontrolador, sin embargo, mostró una capacidad antagónica media en las pruebas in vitro.

Las plantas de romero que contenían los tratamientos de Bacillus spp., con Fusarium spp., no presentaron un grado de severidad alto de marchitez vascular bajo condiciones de invernadero posiblemente porque:

1. Los Bacillus spp., fueron efectivos frente al ataque del hongo mediante la producción de diferentes antibióticos y enzimas que evitaron el crecimiento del hongo.

2. El aislamiento de Fusarium spp., utilizado perdió virulencia y patogenicidad debido a la inhibición enzimática producida por las sucesivas resiembras en medios de cultivo artificiales, que generó cambios metabólicos en éste y por ende un grado de severidad bajo en las plantas inoculadas (39). Autores como Bustamante, ven la necesidad de revirulentar los hongos con fragmentos de tejido asociados a la planta; esto con el fin de mantener activos los genes implicados en la patogénesis y virulencia. La severidad de los síntomas de marchitez vascular varía con el grado de patogenicidad y virulencia de la especie de Fusarium, así como de las condiciones del experimento (40).

3. La agresividad de Fusarium spp., observada bajo condiciones de invernadero no fue la misma a la evidenciada en las pruebas de patogenicidad debido al cambio de las condiciones agroambientales (suelo, temperatura, humedad, luz). La temperatura del suelo pudo no haber sido la adecuada y por ende se vio un retraso en la expresión de síntomas externos, pues según lo reportado a temperaturas menores de $20^{\circ} \mathrm{C}$ la expresión de síntomas de marchitez vascular en las plantas se retrasa considerablemente (16).

4. La técnica de inoculación empleada en este trabajo es considerada confiable para garantizar la presencia del patógeno (16), sin embargo, demostró ser poco eficiente, probablemente porque se realizó inyección del inóculo del patógeno en la base del tallo y no se sumergió la raíz como lo sugieren otros protocolos. Con esta técnica se pudo haber interrumpido el proceso de infección en alguno de los siguientes puntos: a) el reconocimiento de seńales de la raíces de la planta, b) la adhesión a la superficie de la raíz y la diferenciación de hifas de penetración, c) la invasión del cortex de la raíz y la degradación de barreras físicas tales como la de endodermos hasta llegar al tejido vascular, viéndose así afectada la activación de la cascada de señalización MAPK (proteína quinasa activada por mitógenos) esencial en la patogénesis de Fusarium (41).

5. Es posible que la planta de romero haya generado la síntesis de metabolitos secundarios como las fitoalexinas que actúan como mecanismo de resistencia en las plantas, debido a la acción de factores como elicitores o inductores exógenos, producidos por Fusarium, a consecuencia del daño mecánico generada por la inoculación; y endógenos, producidos por las plantas en respuesta a la situación de estrés provocada en el momento de la inoculación $(42,43)$. De tal forma que una alta concentración y acumulación de fitoalexinas pudo inhibir el desarrollo del patógeno (25).

Las plantas inoculadas en el tratamiento con B14 (Bacillus megaterium), mostraron aumento de crecimiento en raíz, probablemente porque los Bacillus spp., y un amplio número de rizobacterias, producen compuestos promotores de crecimiento en plantas como el ácido indol-3-acético (AIA), auxinas, giberelinas y citoquininas que permiten la captación de minerales disponibles como nitrógeno y fósforo en el suelo. La presencia de estos compuestos en la rizósfera parece estimular directamente el crecimiento de la planta (44-46). Bacillus megaterium, ha sido reportado en otros estudios como promotor de crecimiento y modificador de la estructura de la raízy específicamente en Arabidopsis (47) y de giberelinas, fitohormonas 
esenciales que controlan muchos aspectos del desarrollo de la planta que promueven la elongación del tallo, al estimular la división celular $(48,49)$.

Los Bacillus aumentan el peso seco del follaje cuando se utilizan para biocontrol o como bacterias promotoras de crecimiento (PGPR) (50), lo que explicaría los resultados observados en la Figura 9. Los valores de peso seco obtenidos en el control negativo, en los bioensayos y en los tratamientos sugieren que las plantas absorbieron los nutrientes, ascendieron por los haces vasculares y se acumularon principalmente en hojas, probablemente porque la enfermedad aún no se había establecido, si se compara con el control positivo. Los resultados del bioensayo positivo sugieren que los nutrientes no pudieron ascender por los haces vasculares debido al taponamiento ocasionado por la acción patógena del Fusarium, razón por la cual se obtiene un mayor peso en la raíz.

En la comprobación de la presencia del patógeno, éste se recuperó a partir de: el control positivo, confirmando una vez más los postulados de Koch con el cual se comprueba que el Fusarium acuminatum aislado desde un principio es el causante de la marchitez vascular en romero, pues no solamente se demostró su presencia a través del estereoscopio, sino también por medio de la recuperación en medio PDA a partir del tejido vegetal.

En los tratamientos de B1+Fusarium y B2 + Fusarium, no se observaron síntomas que evidenciaran la presencia del patógeno a través del estereoscopio ni tampoco se pudo obtener a partir del cultivo de tejido de romero en medio PDA. En una de las repeticiones del tratamiento de B1 + Fusarium se observó el crecimiento de un micelio blanco, el cual se pensó fuera el patógeno pero al realizar montaje con azul de lactofenol se observó la presencia de micelio estéril, lo cual no permitió identificar el microorganismo. Es posible que las causas estén asociadas con la desintegración de las paredes miceliales que da como resultado la destrucción total de las estructuras celulares de los hongos patógenos, demostrando con ello la particular habilidad de Bacillus spp., para inhibir el crecimiento del patógeno $(30,33,37,51)$ o que el tejido sembrado no estaba afectado por Fusarium.
Los resultados de esta investigación permiten concluir que: Fusarium acuminatum es el agente causal de la marchitez vascular en plántulas de romero (Rosmarinus officinalis) de la Universidad Nacional de Colombia sede Bogotá. Los cuatro aislamientos de Bacillus spp., presentaron actividad antagónica in vitro frente a Fusarium spp., con un porcentaje de inhibición mayor al 45\%, ya que las cuatro especies utilizadas secretan sustancias anti-fúngicas propias del género.

Los cuatro aislamientos de Bacillus spp., presentaron efecto biocontrolador bajo condiciones de invernadero sobre Fusarium spp., en romero al disminuir la severidad de la marchitez vascular en las plántulas por debajo del 50\%, lo que valida los resultados obtenidos en las pruebas in vitro y lo señalado en la literatura acerca de estas bacterias. B14 (Bacillus megaterium) promovió el crecimiento de raíz y tallo en plántulas de romero en comparación con los otros Bacillus bajo condiciones de invernadero.

Se evidenció concordancia entre los resultados obtenidos en la inhibición en las pruebas in vitro y los de severidad bajo condiciones de invernadero en plántulas de romero con Bacillus spp., frente a Fusarium acuminatum. El empleo de Bacillus spp., como microorganismo de biocontrol contra Fusarium acuminatum, demuestra ser una alternativa eficiente para el manejo de éste hongo en plántulas de romero bajo condiciones de invernadero.

Para futuros trabajos se recomienda evaluar en fase de campo los cuatro Bacillus spp., utilizados en este estudio con el fin de corroborar su efecto biocontrolador contra Fusarium spp. Realizar la identificación por medio de técnicas moleculares del aislamiento de Fusarium spp., utilizado con el fin de corroborar la especie de este patógeno, y divulgar el primer reporte de éste en plantas de romero en Colombia. Observar el efecto antagónico de estos Bacillus spp. a diferentes concentraciones contra Fusarium spp., con el fin de estandarizar la técnica a la cual resultan ser más eficiente su inoculación, y finalmente ccaracterizar por PCR los genes que codifican la producción de antibióticos y/o enzimas implicados en la capacidad biocontroladora de los Bacillus spp., utilizados en éste estudio. 


\section{Referencias}

1. Sagorchev P, Lukanov J, Beer AM.. Investigations into the specific effects of rosemary oil at the receptor level. Phytomedicine. 2010;17:693-697.

2. Amado M. Cultivos de más alto valor en Colombia (monografía). Colinagro. 2008.

3. Álvarez-Herrerea J. Rodríguez S, Chacón E. Efecto de diferentes tamaños de esqueje y sustratos en la propagación del romero (Rosmarinus officinalis L). Agronomía Colombiana. 2007;25:224-230.

4. Ciampi L, Silva S. Perspectivas para el control biológico de Botrytis cinerea en frambueso. Rev Aconex. 1991;31:5-10.

5. Martin P, Travers S. Worldwide abundance and distribution of Bacillus thuringiensis isolates. Appl Environ Microbiol. 1989;55:2437-2442.

6. Meadows M, Ellis D, Butt Joe, Jarrett P, Burges H. Distribution, frequency,and diversity of Bacillus thuringiensis in animal feed mill. Appl Environ Microbiol 1992;58:1344-1350.

7. Bernal G, Illanes A, Ciampi L. Isolation and partial purification of a metabolite from a mutant strain of Bacillus sp. with antibiotic activity against plant pathogenic agents. J Biotechnol. 2002;5:7-8.

8. Sánchez L, Corrales L. Evaluación de la congelación para conservación de especies autóctonas bacterianas. Nova. 2005;3:21-29.

9. Benítez S, Bentley J, Bustamante P, Sánchez L, Corrales L. Aislamiento de los microorganismos cultivables de la rizósfera de Ornithogalum umbellatum y evaluación del posible efecto biocontrolador en dos patógenos del suelo. Nova 2007;5:147-153.

10. Mendieta $Y$, Wilches A. Evaluación de posibles microorganismos biocontroladores contra Fusarium oxysporum en rizósfera de Origanum majorana de los invernaderos de la Universidad Nacional. Bogotá, 2009. Informe científico Final (Bacteriólogo y laboratorista clínico). Universidad Colegio Mayor de Cundinamarca. Facultad de Ciencias de la salud

11. Cifuentes J, Jiménez P, Cuervo J, Sánchez L. Evaluación de microbiota de estragon (Artemisa dracunculus L), como aporte al manejo agroecologico de aromaticas en invernaderos de la Universidad nacional. En: Universidad Nacional de Colombia. Perspectivas del agronegocio de hierbas aromáticas culinarias y medicinales. Ed 1. Bogotá, 2007. P. 129 - 133

12. Acosta T, Avellaneda A, Cuervo J, Sánchez L. Evaluacion de microbiota de tomillo (thymus Vulgaris), como aporte al manejo agroecologico de aromaticas en invernaderos de la universidad nacional En: Universidad Nacional de Colombia. Perspectivas del agronegocio de hierbas aromáticas culinarias y medicinales. Ed. 1. Bogotá, 2007. P. 135 - 138

13. Jiménez, Hurtado. Evaluación in vitro la capacidad antagonista de Bacillus subtilis y Bacillus sp., aislados de rizósfera de albahaca (Ocimum basilicum) frente a Fusarium oxysporum. Bogotá, 2008. Informe científico Final. (Bacteriólogo y laboratorista clínico). Universidad Colegio Mayor de Cundinamarca. Facultad de Ciencias de la Salud.

14. Daami-Remadi M. Ayed F, Jabnoun-Khiareddine H, Hibar k, El Mahjoub M. Effects of some Bacillus sp., isolates on Fusarium spp., in vitro and potato tuber dry rot developmet in vivo. Plant Patholo J. 2006;5:238-290.

15. Gaetán S, Madia M. Sclerotinia minor Jagger patógeno de estragón francés y ruso. Bol San Veg Plagas. 1995;21:611-615.

16. Rodríguez M. Determinación de las razas fisiológicas de Fusarium oxysporum f. sp. pisi en las principales zonas productoras de arveja de Cundinamarca y Boyacá. Bogotá, 2006. Informe Científico Final (Master en Ciencias énfasis Fitopatología). Universidad Nacional de Colombia. Facultad de agronomía.

17. Fernández H. Manejo biológico de Phytophthora capsici leo, Fusarium oxysporum schlechted. Fr y Rhizoctonia solani Kuhn en jitomate (Lycopersicon esculentum mil). Revista mexicana de fitopatología. 2007;25:35-42.

18. Carissimi M, Giraudo M, Germani J, Van Der Sand S. Antifungal activity of Bacillus sp., E164 against Bipolaris sorikiniana. Revista Biociencias.2009;17: 48-58

19. Guillen R. Bacillus como biocontrol en un suelo infestado con Fusarium spp, Rhizoctonia solani kuhn y Phytophthora capsici leonian y su efecto en el desarrollo y rendimiento del cultivo de Chile. Rev Fitopatología.2006;24:105-114

20. Castańo J. Principios básicos de fitoepidemiología. Universidad de Caldas. 2002. p. 398.

21. John F. Leslie, Brett A. Summerell. The Fusarium Laboratory Manual. Ed. Blackwell Publishing Professional. USA. 2006

22. Ellis J, Everhart BM. New species of fungi from various localities. J Mycologic. 1895;3:413-441.

23. Ministerio de Comercio, Industria y Turismo. República de Colombia. Comercio exterior Colombia, estadísticas por sector. 2009.

24. Ministerio de Comercio, Industria y Turismo. República de Colombia. Relaciones comerciales Colombia.

25. Agrios G. Plant pathology. Ed 5. Elsevier. 2005

26. Martin P, Travers S. Worldwide abundance and distribution of Bacillus thuringiensis isolates. Appl Environ Microbiol 1989;55:2437-2442.

27. Meadows M, Ellis D, Butt Joe, Jarrett P, Burges H. Distribution, frequency, and diversity of Bacillus thuringiensis in animal feed mill. Appl Environ Microbiol 1992;58:1344-1350.

28. Bernal G, Illanes A, Ciampi L. Isolation and partial purification of a metabolite from a mutant strain of Bacillus sp., with antibiotic activity against plant pathogenic agents. EJB Electronic J Biotechnol. 2002;15:7-8.

29. Lee J, Lee Seon, Kim C, Son J, Song Ju, Jung S, et al. Evaluation of formulations of Bacillus licheniformis for the biological control of tomato gray mold caused by Botrytis cinerea. Biological Control 2006;37:329-337.

30. Gong M, Wang JD, Zhang J, Yang H, Lu XF, Pei Y, et al. Study of the Antifungal Ability of Bacillus subtilis Strain PY-1 in Vitro and Identification of its Antifungal Substance (Iturin A). Acta Biochim Biophys Sin (Shanghai). 2006;38:233-240.

31. Duitman E, Hamoen L, Rembold M, Venema G, Seitz H, Saenger W, et al. The mycosubtilin synthetase of Bacillus subtilis ATCC6633: A multifunctional hybrid between a peptide synthetase, an amino transferase, and a fatty acid synthase. Proc Natl Acad Sci U S A. 1999;96:13294-13299.

32. Romero D, Vicente A, Rakotoaly R, Dufour S, Veening J, Arrebola E, et al. The Iturin and Fengycin Families of Lipopeptides Are Key Factors in Antagonism of Bacillus subtilis Toward Podosphaera fusca. Mol Plant Microbe Interact. 2007;20:430-440.

33. Silo-Suh L, Stabb E, Raffel S, Handelsman J. Target Range of Zwittermicin A, an Aminopolyol Antibiotic from Bacillus cereus. Curr Microbiol. 1998;37:6-11.

34. Chan YA, Boyne MT 2nd, Podevels AM, Klimowicz AK, Handelsman $\mathrm{J}$, Kelleher NL, et al. Hydroxymalonyl-acyl carrier protein (ACP) and aminomalonyl-ACP are two additional type I polyketide synthase extender units. Proc Natl Acad Sci USA. 2006;103:14349-14354.

35. Emmert E, Klimowicz A, Thomas M, Handelsman J. Genetics of Zwittermicin A Production by Bacillus cereus. Appl Environ Microbiol. 2004;70:104-113.

36. Kiss A, Baliko G, Csorba A, Chuluunbaatar T, Medzihradszky K, Alfo L. Cloning and Characterization of the DNA Region Responsible for Megacin A-216 Production in Bacillus megaterium. J Bacteriol. 2008;190:6448-6457.

37. Carlton B, Helinsk D. Heterogeneous circular DNA elements in Vegetative cultures of bacillus megaterium. Proc Natl Acad Sci USA. 1969;64:592-599.

38. Bapat $S$, Shah AK. Biological control of fusarial wilt of pigeon pea by $B a-$ cillus brevis. Can J Microbiol. 2000;46:125-132.

39. Troya MT, Navarrete A. Nota sobre análisis de la virulencia de Coniophora puteana (Schumacher ex Fries) Karsten, Gloeophyllum trabeum (Persoon ex Fries) Murrill y Postia placenta (Fr.) M.J. Lars et Lomb. En diferentes medios de cultivo. Invest Agrar Sist Recur . 1992;16:10-91.

40. Quilambaqui M, Zavaleta E, Mora G, Delgadillo F, Marín A. Patogenicidad de tres especies de Fusarium asociadas con el declinamiento del esparrago (Asparagus oficcinalis L.) en Guanajuato, México. Rev Mexicana Fitopatol. 2004;22:30-36. 
41. Di Pietro A, González M. Fusarium oxysporum: un modelo para el análisis de la patogénesis fúngica en plantas y humanos. Boletín Informativo de la Sociedad Española de Microbiología. 2004;37:6-13.

42. García M, Pérez R. Fitoalexinas: mecanismo de defensa de las plantas. Rev Chapingo. 2003;9:5-10.

43. Kloepper J, Ryu C, Zhang S. Induced Systemic Resistance and Promotion of Plant Growth by Bacillus spp. Phytopathology. 2004;94:1259-1266.

44. Brimecombe M, Leij F, Lynch J. Rhizo depositión and microbial populations. En: Pintón Robertop. The Rizosphere. Ed. 2. Taylor \& Francis Group; 2007.p. 74-98.

45. Shuai W, Wu H, Qiao J, Ma L, Liu J, Xia Y, et al. Molecular Mechanism of Plant Growth Promotion and Induced Systemic Resistance to Tobacco Mosaic Virus by Bacillus spp. J Microbiol Biotechnol. 2009;19:1250-1258.

46. Fernández A, Villaverde M, Casanova J, Malo J, Nicolas JA, et al. Nuevo aislado de Bacillus y su utilización para el control de hongos fitopatógenos. Agroecologia.net. 2004;6:50-57.
47. López J, Campos J, Valencia E, Velázquez C, Farias R, Macias I. Bacillus megaterium modifica la arquitectura de la raíz de Arabidopsis independientemente de auxinas y etileno. Rev Bilógicas. 2009;9:1-8.

48. Alan A, Baulcombe D, Harberd N. Modulation of floral development by a gibberellin-regulated microRNA. Development. 2004;131:3357-3365.

49. Gil J, Young K, In-Jung L, Kyung S, In-Koo R. Growth promotion of red pepper plug seedlings and the production of gibberellins by Bacillus cereus, Bacillus macroides and Bacillus pumilus. Biotechnol Lett. 2004;26:487-491.

50. Lagunas J, Zavaleta E, Osada S, Aranda S, Luna I, Vaquera H. Bacillus firmus como agente de control biológico de Phytophthora capsici Leo. Rev Mexicana Fitopatol. 2001;19:57-65.

51. Basurto M, Font M, García J, Vázquez M. Cambios en la estructura celular durante la actividad antagónica de Bacillus subtilis contra Rhizoctonia solani y Fusarium verticillioides. Acta Microscópica. 2010;19:138-144. 